\section{ENSEÑANZA DE LENGUAS ORIGINARIAS EN LAS FACULTADES DE MEDICINA PERUANAS}

\section{TEACHING INDIGENOUS LANGUAGES AT PERUVIAN MEDICAL SCHOOLS}

\author{
Gabriela Santos-Revilla ${ }^{1, a}$
}

\author{
${ }^{1}$ Sociedad Científica de Estudiantes de Medicina, Universidad \\ de San Martín de Porres. Lima, Perú. \\ a Estudiante de Medicina
}

Sr. Editor. De acuerdo al Censo Nacional de Población y Vivienda del año 2007 , el $15,9 \%$ de peruanos tiene como lengua materna un idioma o lengua nativa. Existen 47 lenguas originarias vigentes en nuestro país (43 amazónicas y 4 andinas), que se hallan dispersas en todos los departamentos del Perú, donde el quechua es la lengua originaria mayormente hablada (3 360331 personas) ${ }^{(1)}$.

Se realizó una búsqueda en los planes de estudio disponibles virtualmente de las facultades de Medicina de las universidades miembros de la Asociación Peruana de Facultades de Medicina (ASPEFAM), comparando el número de facultades de Medicina y lenguas originarias de enseñanza por regiones. Solo tres facultades enseñan lenguas originarias (Tabla 1).

Tabla 1. Facultades de Medicina y lenguas originarias de enseñanza según regiones de Perú (1)

\begin{tabular}{lccc}
\hline \multicolumn{1}{c}{ Región } & $\begin{array}{c}\text { Facultades } \\
\text { de } \\
\text { Medicina }\end{array}$ & $\begin{array}{c}\text { Lengua } \\
\text { originaria de } \\
\text { enseñanza }\end{array}$ & Condición \\
\hline Ancash & 1 & Ninguna & - \\
\hline Arequipa & 2 & Ninguna & - \\
Cajamarca & 1 & Ninguna & - \\
Cusco* & 1 & Quechua & Obligatorio \\
Ica & 1 & Ninguna & - \\
\hline Junín & 2 & Ninguna & - \\
La libertad & 2 & Ninguna & - \\
Lambayeque & 1 & Ninguna & - \\
Lima & 9 & Quechua & Uno electivo y \\
\hline Loreto & 1 & Ninguna & - \\
\hline Piura & 2 & Ninguna & - \\
\hline Puno & 1 & Ninguna & - \\
\hline Tacna & 1 & Ninguna & - \\
\hline
\end{tabular}

*Según la búsqueda, Cusco es la única región donde la enseñanza de quechua es obligatoria
En Perú se ha recomendado incluir al quechua como parte de la enseñanza de los estudiantes de Medicina ${ }^{(2)}$. Además, la Organización Mundial de la Salud (OMS) propuso como sugerencia la revisión de los planes de estudio de las carreras sanitarias para integrar capacidades útiles a la práctica rural, considerando, incluso, la admisión selectiva de estudiantes con orígenes rurales, como factor fuertemente asociado a su permanencia en este sector ${ }^{(3)}$. Asimismo, se sugiere que el conocimiento de una lengua oriunda es un factor asociado a la decisión de trabajar en el interior del país ${ }^{(2)}$.

En un estudio boliviano (4) se encontró que personal sanitario no conocía el idioma de la población, situación que creaba una comunicación ineficiente e, incluso, irrespetuosa con su cultura; lo que conlleva a graves consecuencias en su atención por las demoras y obstáculos implicados, ocasionando desde la discriminación a las pacientes obstétricas hasta la muerte perinatal y materna. Más allá de la falta de equipo médico, de instalaciones u otras razones netamente hospitalarias, se señaló que era la brecha intercultural la que limitaba la atención de las pacientes. En efecto, en un estudio peruano realizado en profesionales de la salud que ejercían el Servicio Rural y Urbano Marginal de Salud (SERUMS), el 55\% señaló el desconocimiento del idioma quechua como una de las principales dificultades en el desarrollo de su trabajo ${ }^{(5)}$.

El poder adquirir las destrezas necesarias para una comunicación verdadera con los 4102405 habitantes que hablan las lenguas originarias en Perú (1), permitiría no solamente mejorar la relación médico-paciente sino asegurarles el ejercicio pleno de sus derechos en salud. Más allá de poder entablar una conversación fructífera con los pacientes, hablar su idioma representa el respeto a sus diferencias y la aproximación humanizada a su salud y cultura. Se resalta la urgencia de la implementación de, al menos, una lengua originaria en el currículo de los profesionales de la salud, especialmente en las facultades de Medicina, sobre todo en aquellas con ubicación en los departamentos de mayor densidad lingüística.

Fuentes de financiamiento: autofinanciado por la autora.

Conflictos de interés: la autora declara no tener conflictos de interés.

\footnotetext{
Sociedad Científica de Estudiantes de Medicina, Universidad de San Martín de Porres. Lima, Perú.

a Estudiante de Medicina

Recibido: 20-11-15 Aprobado: 16-12-15
}

Citar como: Santos-Revilla G. Enseñanza de lenguas originarias en las facultades de medicina peruanas. [carta]. Rev Peru Med Exp Salud Publica. 2016;33(1): 183-4. doi: 10.17843/rpmesp.2016.331.2021 


\section{REFERENCIAS BIBLIOGRÁFICAS}

1. Sullón-Acosta K, Huamancayo-Curi E, Mori-Clement M, Carbajal-Solis V. editores. Documento Nacional de Lenguas originarias del Perú. Ministerio de Educación: Lima; 2013.

2. Mayta-Tristán P, Mejia CR, Riega-Lopez P, Rojas-Mezarina L, Posso M, Mezones-Holguín E. Proyección de trabajo en el interior del país y factores asociados en médicos recién colegiados de Lima, Perú 2010. Rev Peru Med Exp Salud Publica. 2011;28(2):186-93.

3. World Health Organization. Increasing access to health workers in remote and rural areas through improved retention. Geneva: WHO; 2010.

4. Roosta-G M. Madres indígenas enfrentan más de tres demoras: Los desafíos de la interculturalidad en salud. J Selva Andina Res Soc. 2015;6(2):64-74.
5. Valencia Teresa, Leon B, Lezameta U, Vidal M. Principales dificultades del profesional de salud encontrados durante el Serums en el departamento de Ancash, zona sierra. 2008. Rev Aporte Santiaguino. 2011;4(1):118-22.

Correspondencia: Gabriela del Carmen Santos Revilla

Dirección: Calle Rio Rin 129 urb. Las Praderas de La Molina. Lima, Perú.

Teléfono: (511) 998068006

Correo electrónico: gabriela.sr92@gmail.com

https://www.youtube.com/RPMESP

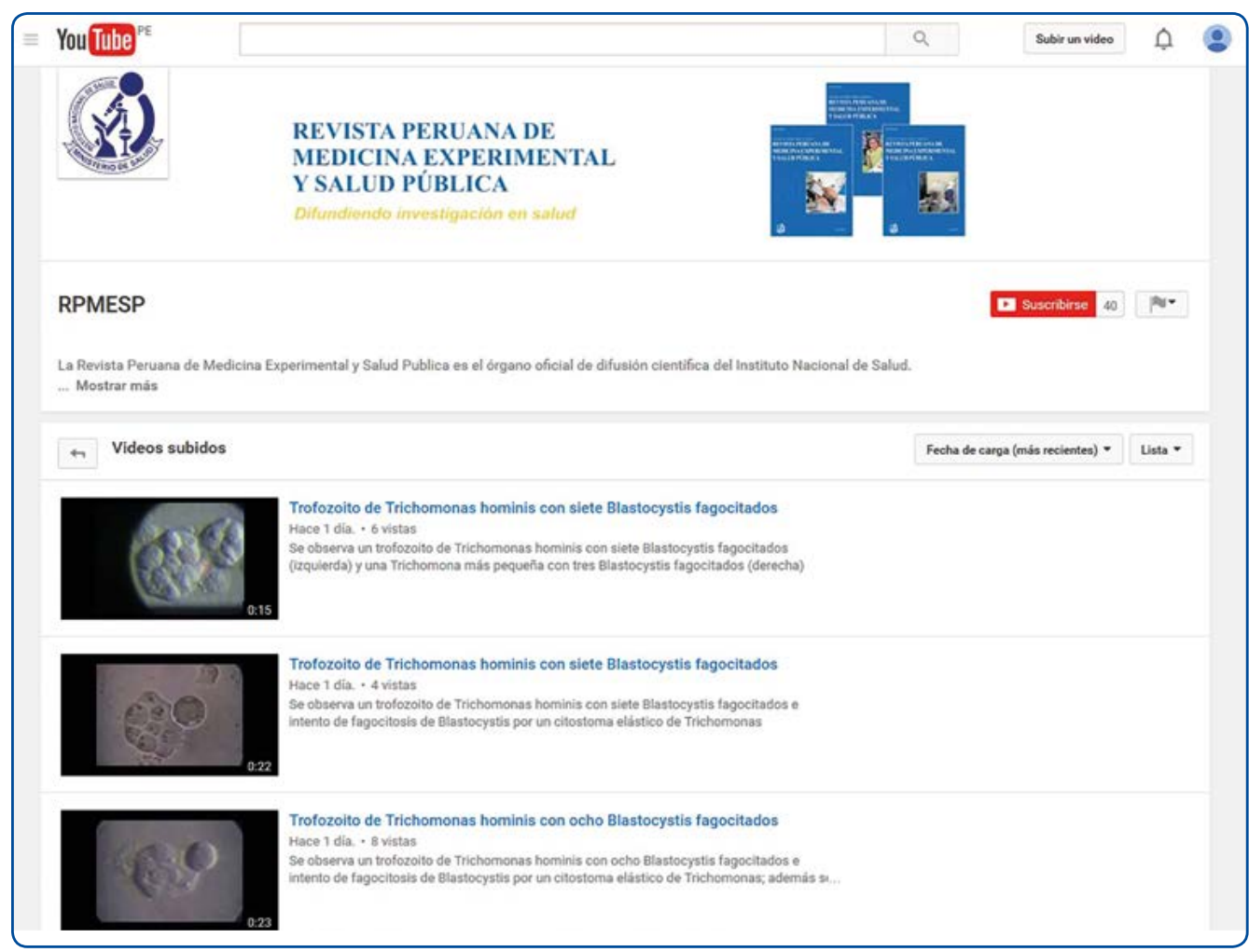

